\title{
Aportes para el reproyecto de conjuntos habitacionales vulnerables. Micro acciones que promueven la exterioridad
}

\author{
Contributions for the re-draft of vulnerable housing \\ states. Micro-actions that promote exteriority"
}

\author{
Andrés Cabrera Recoba ${ }^{1}$ \\ Fecha de recepción: 15-03-2021 - Fecha de aceptación: 09-04-2021 \\ Hábitat y Sociedad (ISSN 2173-125X), n. ${ }^{\circ}$ 14, noviembre de 2021, pp. 339-352. \\ https://doi.org/10.12795/HabitatySociedad.2021.i14.018
}

\section{Summary}

The activation of public housing states from the $70 \mathrm{~s}$ and 80 s decades, currently under vulnerability processes, presents itself as a form of urban sustainability that takes advantage of existing buildings and infrastructure for the generation of quality housing and habitat.

A small scale project is proposed here as an intervention strategy. Micro-actions based on the incorporation of activating elements, capable of generating greater unfolding in the different scales of the housing state, through the co-operative participation of its dwellers, creating a renovated bond with objects and spaces in the state.

The investigation addresses 9 housing states in Montevideo and in this article we focus on the exteriority of domestic sceneries, understood as living the outdoors. Looking out the window, going out to the balcony, to the ground floor, walking along a corridor street, going through internal paths until reaching an urban street; daily experiences based on having the user as the center.

A bridge is a man crossing a bridge. ${ }^{2}$

Key words

Activator; Multiscale; Exteriority; Housing

\section{Resumen}

La activación de los conjuntos de vivienda pública de las décadas de los 70 y 80 , actualmente con procesos de vulnerabilidad, se presenta como una forma de sostenibilidad urbana que aprovecha las edificaciones y las infraestructuras instaladas para la generación de viviendas y hábitat de calidad.

Se propone el proyecto de pequeña escala como estrategia de intervención. Micro acciones a partir de la incorporación de elementos activadores capaces de generar despliegues mayores en las distintas escalas del conjunto con la participación cooperativa de los habitantes produciendo un vínculo renovado con los objetos y espacios del conjunto.

La investigación aborda 9 conjuntos habitacionales de Montevideo y en este artículo haremos foco en la exterioridad de los escenarios domésticos, entendida como vivir con el afuera. Mirar por la ventana, salir al balcón, ir a la planta baja, caminar por una calle corredor, atravesar los pasajes internos hasta llegar a la calle urbana, experiencias cotidianas basadas en el usuario como centro.

Un puente es un hombre cruzando un puente. ${ }^{2}$

Palabras clave

Activador; Multiescalar; Exterioridad; Habitacional

1 FADU, Udelar, Montevideo, Uruguay. E-mail: andres@cdbarquitectos.com. ORCID: https://orcid.org/0000-0002-0686-2029.

2. Julio Cortázar, Libro de Manuel, p. 27, 1973. 


\section{De micro acciones a sostenibilidad urbana}

En Montevideo en las décadas de los setenta y ochenta se construyeron al menos 80 Conjuntos Habitacionales, CHs, de promoción pública, entre los cuales aproximadamente 30 son del modelo de bloques, representando estos últimos alrededor de 8500 viviendas. En 9 de estos conjuntos la Agencia Nacional de Vivienda (ANV) ha identificado situaciones de vulnerabilidad a partir de evaluaciones que incluyen aspectos territoriales, sociales, jurídico-notariales, económicos y arquitectónicos.

Estos 9 conjuntos "vulnerables" constituyen el objeto de estudio de esta investigación en desarrollo en el marco del Doctorado en Arquitectura $^{3}$ de la Facultad de Arquitectura, Diseño y Urbanismo, FADU, de Montevideo, Uruguay.

El problema no se resume a patologías de los edificios por falta de mantenimiento, estos conjuntos definen "islas urbanas" con una implantación autónoma que provoca discontinuidades con el tejido existente. El modelo de bloque sobre el verde impone una división tajante entre el espacio privado del interior de los bloques y el espacio "colectivo" compuesto por áreas remanentes de uso indefinido entre las construcciones y las calles internas. Se suma a estos problemas la dudosa capacidad de las viviendas de satisfacer las necesidades contemporáneas en cuanto a confort, espacio, servicios, accesibilidad y prestaciones generales a los heterogéneos grupos familiares que los habitan. Esta investigación pretende contribuir, desde el proyecto, al debate sobre la pertinencia de intervenir sobre las estructuras residenciales en proceso de degradación física y social, que constituyen un patrimonio construido, cuantitativamente relevante para el Uruguay, que se debe no solo resguardar, sino también mejorar como práctica de sostenibilidad urbana.

El trabajo plantea la hipótesis que es posible disparar procesos de mejora significativos en la habitabilidad de estos conjuntos a partir de estrategias de intervención basadas en micro proyectos que denominaremos activadores, derivados de la lectura de un Método de Análisis Multiescalar, MAM, que se aplicó a los 9 CHs.

Entendemos que hay un potencial poco explorado en la forma de intervenir con micro proyectos que proponemos, que es complementaria de otras acciones que deberán ser planificadas por el Estado.

La investigación se apoya en el proyecto como modo de pensamiento y como instrumento de carácter propositivo, que articula las distintas variables, escalas del problema y el modo de gestión.

Las bases conceptuales del trabajo son las proposiciones de Lacaton \& Vassal con Fréderic Druot (2007), en Plus-Territorio de Excepción y las ideas de intervención sobre áreas degradadas de Héctor Vigliecca (2012), El tercer territorio, entendido como el resultado de intervenir manteniendo y reconociendo los elementos materiales e inmateriales de los barrios, reivindicando el valor del proyecto como factor de cambio.

La noción de activador propuesta refiere al potencial transformador de una intervención de pequeña escala asociada a la idea de Arquitectura Enzimática (Borrego, 2006).

Una enzima es una biomolécula necesaria en las reacciones químicas por ser capaz de aumentar su rapidez, una pequeña proteína con consecuencias esenciales en todo el organismo.

De la misma manera se producen a nuestro alrededor acciones cataliza-

$3 \quad$ La tesis es dirigida por la Dra. Arq. Alina del Castillo y codirigida por el Dr. Arq. Rubén Otero. doras de pequeña escala en proporción a los grandes efectos que generan (Borrego, 2006, p. 2). 
Los micro proyectos que operan como activadores se apoyan en los principios y métodos del urbanismo táctico de distintos colectivos activistas, basados en procesos de transformación del contexto a partir de pequeñas intervenciones de carácter colaborativo, y en las ideas de $R e-$ habitar (Monteys et al., 2010) que pone el énfasis en visiones alternativas de uso y en los habitantes en lugar de la arquitectura.

El análisis del MAM es una disección gráfica en distintas escalas que se sirve del redibujo, el relevamiento fotográfico y la visita. Se proponen cinco escalas: XS-componente, S-unidad, M-bloque, L-conjunto y XL-área de 1000x1000m y cuatro líneas temáticas: Exterior, Interior, Equipamiento e Instalaciones (Cuadro 1), para luego desdoblarse en meta-proyectos y micro acciones.

Desde el punto de vista metodológico, el método de análisis de los conjuntos habitacionales se apoya principalmente en el estudio " $I+D+S$ : Futuros de la vivienda social en 7 ciudades", (2009).

\begin{tabular}{|c|c|c|c|c|c|c|}
\hline ENCUADRES TEMÁTICOS & XS / COMPONENTE: $1 \times 1 \mathrm{~m}$ & S/UNIDAD: $10 \times 10 \mathrm{~m}$ & M / BLOQUE: 20×20m(Variable) & L/ CONJUNTO: 250×250m(Var.) & XL / ÁREA: $1000 \times 1000 \mathrm{~m}$ & INSTRUMENTOS \\
\hline EXTERIOR $_{\text {X }}$ & $\begin{array}{l}\text { LA VENTANA } \\
\text { ABERTURAS INTERIORES POR TIPO } \\
\text { DIMENSIONES / RELACION CON } \\
\text { EL MURO QUE LA CONTIENE I } \\
\text { PROPORCIÓN LLENO-VACIO DE } \\
\text { FACHADA }\end{array}$ & $\begin{array}{l}\text { TERRAZA / BALCÓN / PATIO } \\
\text { ESPACIOS ABIERTOS DE LA UNIDAD } \\
\text { LA TERRAZA DE SERVICIO YEL } \\
\text { BALCÓN: DIMENSIONES Y USOS. } \\
\text { CONEXIÓN CON LA HABITACIÓN } \\
\text { INTERIOR }\end{array}$ & $\begin{array}{l}\text { PLANTA BAJA-CIRCULACIÓN } \\
\text { CUBIERTA } \\
\text { ACCESOS, MATERIALIDAD, AREA } \\
\text { CIRCUITO DE ACCESO DE PLANTA } \\
\text { A LA UNIDAD } \\
\text { DIMENSIONES Y ELEMENTOS DEL } \\
\text { ACCESO / ESCALERA }\end{array}$ & $\begin{array}{l}\text { ESPACIOS EXTERIORES DEL } \\
\text { CONJUNTO } \\
\text { AREA CONSTRUIDA / AREA LIBRE / } \\
\text { CALLES INTERNAS / ESPACIOS } \\
\text { ARQUITECTURIZADOS } \\
\text { POROSIDAD DE LA RED VIAL } \\
\text { INTERNA / ECONOMIA DE LA URBA- } \\
\text { NIZACION SUP. EDIFICADASUP. } \\
\text { VIARIO }\end{array}$ & $\begin{array}{l}\text { EL ESPACIO PÚBLICO } \\
\text { CALLES DEL ENTORNO / CONECTI- } \\
\text { VIDAD / PROPORCIÓN CONST.IESP. } \\
\text { LIBRE, F.O.S. DEL AREA } \\
\text { ESPACIOS VACANTES. } \\
\text { POROSIDAD DE LA RED VIAL/ } \\
\text { DIMENSIONES DE LAS MANZANAS } \\
\text { URBANIDAD }\end{array}$ & \multirow{4}{*}{$\begin{array}{l}\text { GESTIÓN: } \\
\text { PARTICIPACIÓN, } \\
\text { COOPERATIVIZACIÓN } \\
\text { INTERACIÓN DE } \\
\text { ACTORES: DEL } \\
\text { USUARIO AL SISTEMA } \\
\text { PÚBLICO }\end{array}$} \\
\hline NTERIOR & $\begin{array}{l}\text { MURO EXTERIOR, TABIQUES, } \\
\text { Y ABERTURAS INTERIORES } \\
\text { COMPOSICIOON MATERIAL DE MUROS } \\
\text { Y TABIQUES } \\
\text { ABERTURAS INTERIORES: PUERTAS } \\
\text { CAPACIDAD ESTRUCTURAL }\end{array}$ & $\begin{array}{l}\text { HABITACIONES / VIVIENDAS } \\
\text { AREA INTERIOR CONSTRUIDAY } \\
\text { USOS PRE DEFINIDOS } \\
\text { LA ALTURA PISO-TECHO. } \\
\text { TIPOLOGIAS Y UNIDADES DE } \\
\text { AGREGACION } \\
\text { ÁREA Y VOLUUMEN POR PERSONA } \\
\text { DENSIDAD POR VIVIENDA }\end{array}$ & $\begin{array}{l}\text { EL SISTEMA: VIVIENDA Y OTROS } \\
\text { USOS EN EL BLOQUE } \\
\text { EL BLOQUE COMO SISTEMA DE } \\
\text { UNIDADES DE AGREGACIÓN }\end{array}$ & $\begin{array}{l}\text { EL MODELO: VIVIENDA Y OTROS } \\
\text { USOS EN EL CONJUNTO } \\
\text { EL CONJUNTO COMO MODELO DE } \\
\text { "BLOQUES SOBRE EL VERDE" } \\
\text { USOS DEL SUELO, ORIGINAL Y } \\
\text { AGREGADO / CONSTRUCCIONES } \\
\text { IRREGULARES } \\
\text { TESTEROS Y ESPACIO "SOMBRA" } \\
\text { ESPACIO-SUELO PARA AMPLAACIÓN } \\
\text { DENSIDAD DEL CONJUNTO }\end{array}$ & $\begin{array}{l}\text { USOS DEL SUELO EN EL ÁREA } \\
\text { PARCELARIO } \\
\text { HÁBITAT Y VIVIENDA EN EL ÁREA } \\
\text { ASENTAMIENTOS IRREGULARES } \\
\text { PROGRAMAS COLECTIVOS PRINCI- } \\
\text { PALES } \\
\text { EDIFICABILIDADA BRUTA / FOS }\end{array}$ & \\
\hline JIPAMIENTOS & $\begin{array}{l}\text { EL MUEBLE } \\
\text { LOS ELEMENTOS COMPLEMENTA- } \\
\text { RIOS / } \\
\text { EL MUEBLE FIJO YEL MUEBLE } \\
\text { MÓVIL: DISPOSICIONES }\end{array}$ & $\begin{array}{l}\text { HABITACIONES PRE EQUIPADAS: } \\
\text { BAÑO Y COCINA } \\
\text { CONFORMACIÓN/ UBICACIÓN / } \\
\text { REVESTIMIENTOS }\end{array}$ & $\begin{array}{l}\text { EQUIPAMIENTO COLECTIVO EN } \\
\text { EL BLOQUE } \\
\text { LA ESCALERA COMO DISPOSITIVO } \\
\text { DE EQUIPAMIENTO COLECTIVO }\end{array}$ & $\begin{array}{l}\text { EQUIPAMIENTO COLECTIVO } \\
\text { EQUIPAMIENTO Y ZONAS ARQUITEC- } \\
\text { TURIZADAS EN EL CONJUNTO } \\
\text { ESPACIO PARA EL AUTO } \\
\text { EL ARBOL COMO EQUIPAMIENTO }\end{array}$ & $\begin{array}{l}\text { EQUIPAMIENTO COMUNITARIO } \\
\text { ARBOLADO PÚBLICO } \\
\text { ALUMBRADO PÚBLICO } \\
\text { TIPOS DE CALLE Y PAVIMENTOS }\end{array}$ & \\
\hline \multirow[t]{2}{*}{$\begin{array}{l}\text { INSTALACIONES I } \\
\text { INFRAESTRUCTURAS }\end{array}$} & $\begin{array}{l}\text { LA VENTANA Y EL MURO } \\
\text { CAPACIDAD TÉRMICA DEL MURO Y } \\
\text { VENTANA: TRANSMITANCIA TÉRMICA } \\
\text { PROTECCIONES DE LAS ABERTURAS } \\
\text { EL CORTE INTEGRAL }\end{array}$ & $\begin{array}{l}\text { INSTALACIONES DE LA UNIDAD } \\
\text { SANITARIA } \\
\text { VENTILACIÓN Y CIRCUITO NATURAL } \\
\text { DE AIRE }\end{array}$ & $\begin{array}{l}\text { ENVOLVENTE } \\
\text { FACTOR DE FORMA: PORCENTAJE } \\
\text { DE HUECOS DE LA ENVOLVENTE } \\
\text { DEL BLOQUE } \\
\text { ESTRUCTURA } \\
\text { ACOMETIDAS DE INSTALACIONES } \\
\text { SANITARIA YELEECTRICA }\end{array}$ & $\begin{array}{l}\text { SUELO Y REDES } \\
\text { TOPOGRAFIA DEL ÁREA } \\
\text { INSTALACIONES DEL CONJUNTO }\end{array}$ & $\begin{array}{l}\text { INFRAESTRUCTURAS BÁSICAS } \\
\text { SANEAMIENTO } \\
\text { RECOLECCIÓN DE RESIDUOS } \\
\text { TRANSPORTE PÚBLICO }\end{array}$ & \\
\hline & & RANGO 1:EDILICIO & & RANGO 2: CONJUNTO & RANGO 3 : AREA & \\
\hline
\end{tabular}

\section{Gestión de adentro hacia afuera. Lo cooperativo- participativo}

Cuadro 1: Método de Análisis Multiescalar-MAM. Fuente: Elaboración propia.

La amplia experiencia uruguaya del Cooperativismo de vivienda demuestra que la participación de los usuarios en la toma de decisiones, la gestión y la producción del hábitat genera capacidades y es un factor relevante en el fortalecimiento del vínculo entre los vecinos y de estos con el conjunto. Este vínculo que comienza antes de la ejecución de la obra y que se mantiene durante la construcción se constituye en el elemento fundamental para la conservación, mantenimiento y mejora de los edificios y espacios comunes posterior a la ocupación de las viviendas.

En su tesis doctoral López Medina (2012) se apoya en los conceptos de Víctor Saúl Pelli (2010) sobre gestión participativa y concertada de los habitantes. En esta línea de pensamiento no sería utópico pensar en la transferencia de capacidades del Cooperativismo a estos colectivos de escasa cohesión social, a través de procesos de formación conducidos 


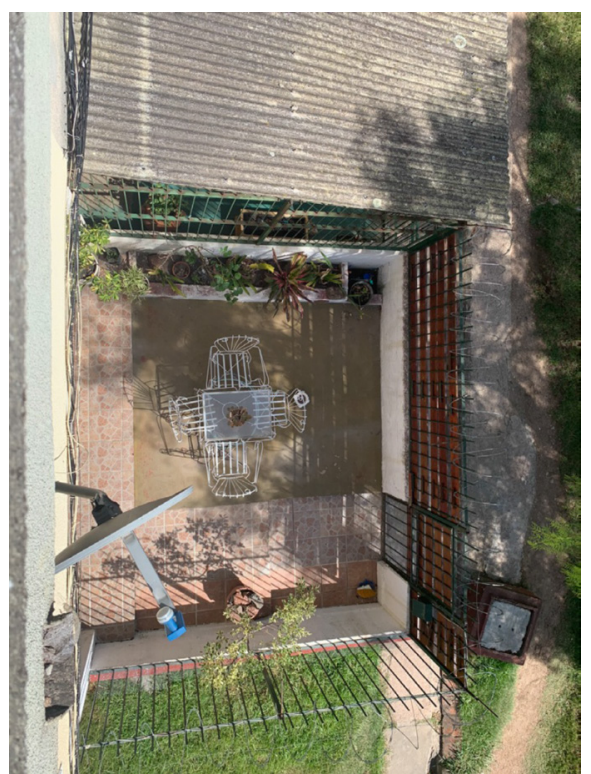

Figura 1: Patio en $\mathrm{CH}$ 25-33-42. Fuente: Fotos G. Ré. por equipos técnicos multidisciplinarios operando desde las distintas escalas implicadas (vecinos, unidades de agregación, bloques, conjunto $\mathrm{y}$ otros colectivos)

\section{Exterioridad}

Vivir afuera. Micro acciones transformadores del ámbito exterior de la vida en los CHs (Figura 1).

\section{Escala XS_Ventanas}

Las ventanas, a diferencia de las puertas, se manipulan solo desde el interior con el propósito de establecer contacto con el exterior desde adentro de la vivienda, desde el dominio privado.

La ventana es el medio de regulación de la luz, el aire y el calor como elementos fundamentales para la vida humana. Es también el espacio de contacto visual con el entorno, el cielo, las copas de los árboles y todo lo construido y no construido de la ciudad. La ventana es un puesto de control y es un elemento de comunicación. Las ventanas son como los poros de la piel, elementos de intercambio.

En los conjuntos en estudio el tamaño de las ventanas es de $1,5 \mathrm{~m}^{2}$ promedio por habitación y el porcentaje de vano del 18\%, con un entorno de implantación de dos niveles en su mayor parte (Figuras 2 y 3 ).
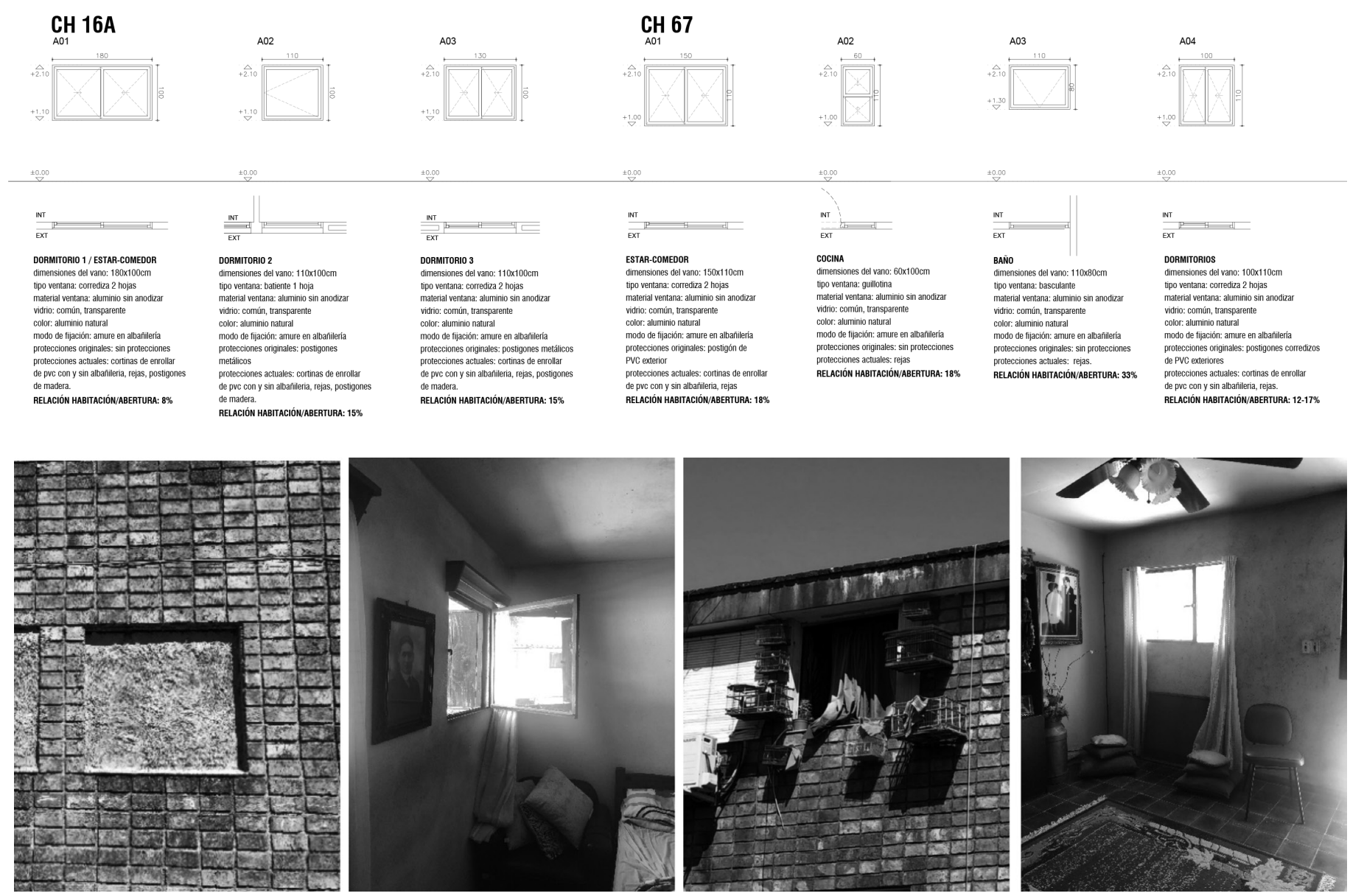

Figura 2 [arriba]: Ventanas, MAM, Tema: Interior, XS, CH16 A y CH67. Fuente: Elaboración propia. Figura 3 [abajo]: Ventanas en los CHs. Fuente: Fotos G. Ré y F. Cabrera. 
Activaciones. Ampliar ventanas

En la vivienda social ha existido siempre por parte de los promotores públicos el convencimiento que la abertura pequeña es de menor costo y mejor aún si esta no llega hasta el piso.

La modificación de las ventanas para convertirlas en aberturas más grandes permite conectarse mejor con el exterior y habilita la creación de espacios exteriores como el balcón.

\section{Escala S_Balcón}

En la mayoría de los CHs se encuentra una terraza de servicio, más o menos oculta donde se agrupan máquinas de lavado de ropa, tendederos, unidades exteriores de aire acondicionado y también todos los despojos que el interior es incapaz de contener, convirtiéndose en lugar de acumulación de cosas que se usan poco o no se usan. Casi nunca es posible caminar en estos espacios, apenas estar parados, y muchas veces se camufla con cerramientos permeables al viento y no tanto a la luz. Otras veces los habitantes lo integran al interior de la cocina para ampliar su área, desplazando las funciones de tendido de ropa a la fachada, en todos los casos son espacios poco asociables a la idea de espacio exterior para habitar. En los conjuntos en estudio se verifican los siguientes tipos de balcones-terrazas: la terraza de servicio contenida en el volumen del bloque, el balcón conformando un volumen saliente, la terraza-balcón continua y la calle corredor (Figuras 4 y 5 ).

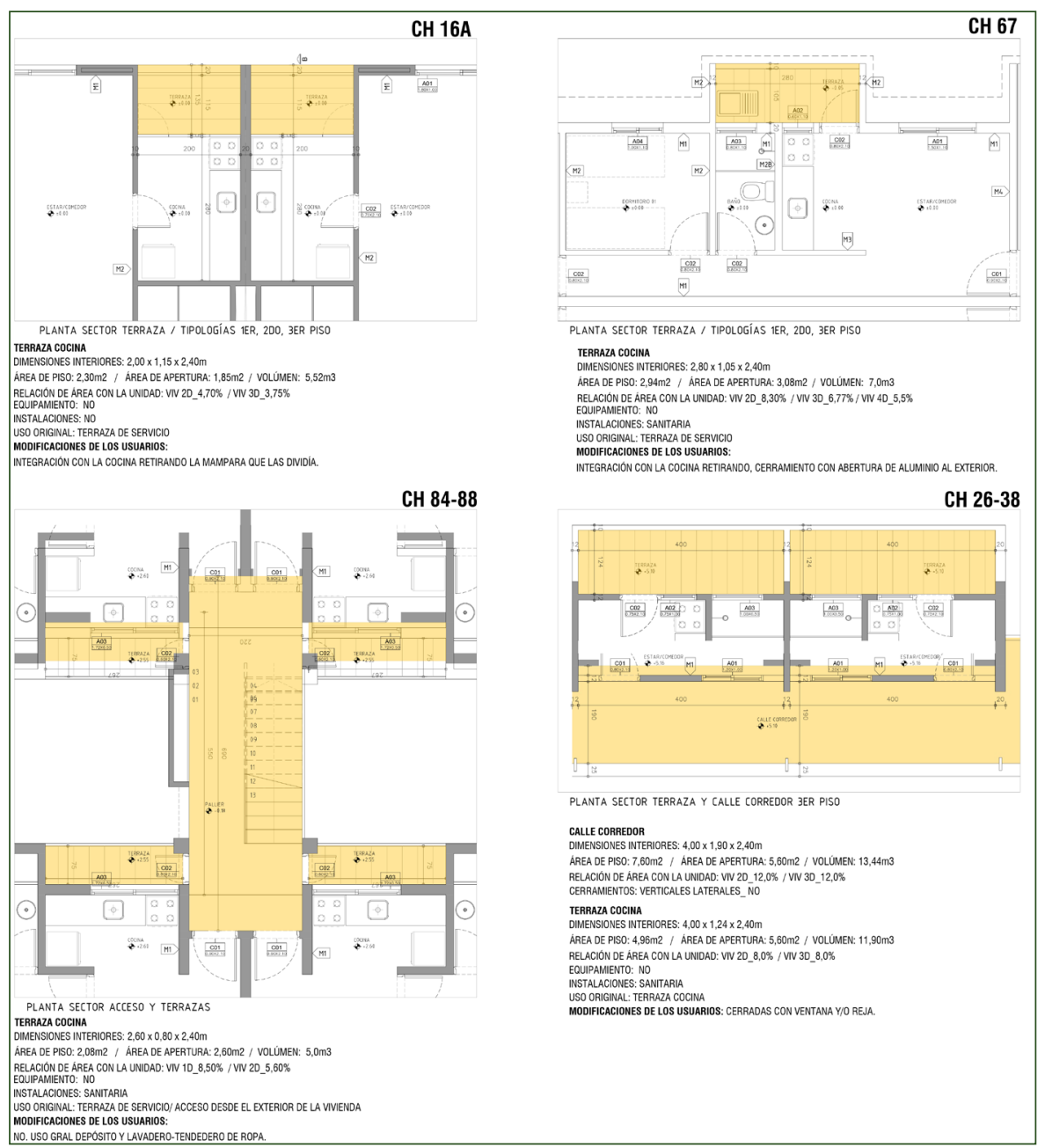

Figura 4: Terrazas-balcones, MAM, Tema: Interior, S, CH 16A, CH 67, CH 26-38 y CH 84-88. Fuente: Elaboración propia. 


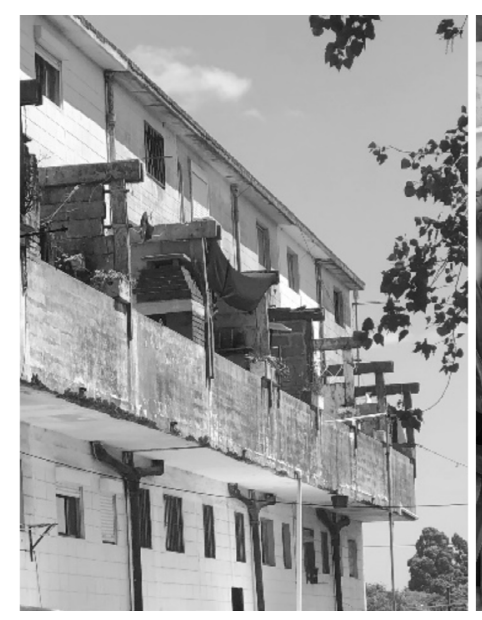

Figura 5: Terrazas en los CHs. Fuente: fotos $G$. Ré y F. Cabrera.

Figura 6: Testeros, MAM, Tema: Interior, M, CH16 A y CH67. Fuente: Elaboración propia.

\section{CH 16A}
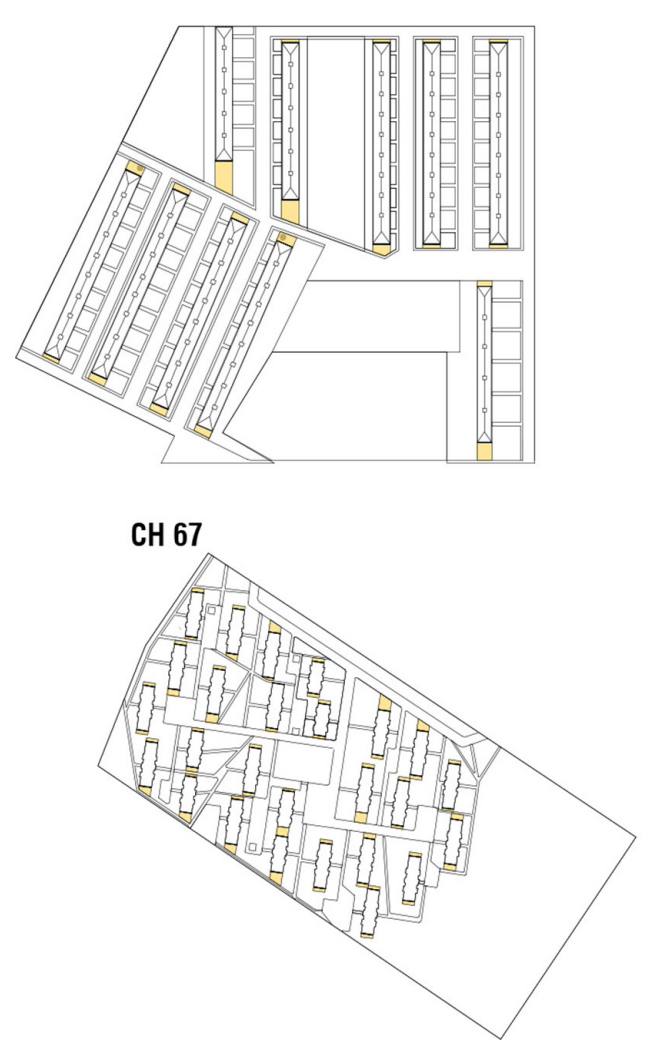

Activaciones. La habitación exterior

El balcón puede ser una habitación exterior (Monteys et al., 2010), un espacio habitable exterior como expansión del interior a modo de patios, pero en altura, un espacio activo para entrar y salir vinculado a un ascensor agregado, un espacio de contemplación, de plantas, de sol y aire, un espacio Plus (Lacaton et al., 2007) multipropósito, un jardín, una extensión del estar, un muelle sobre el verde.

\section{Escala M_Espacio Testero y espacio terraza}

Independiente de la geometría, dimensiones y ubicación del predio en la ciudad, los bloques se implantan con las fachadas principales hacia el este y oeste para asegurar asoleamiento en la mañana o la tarde. La tercera y cuarta fachada, los testeros, uno al norte y otro al sur no tienen aberturas y muchas veces enfrentan a espacios exteriores residuales. Se reconoce un gran potencial en el binomio testero-espacio
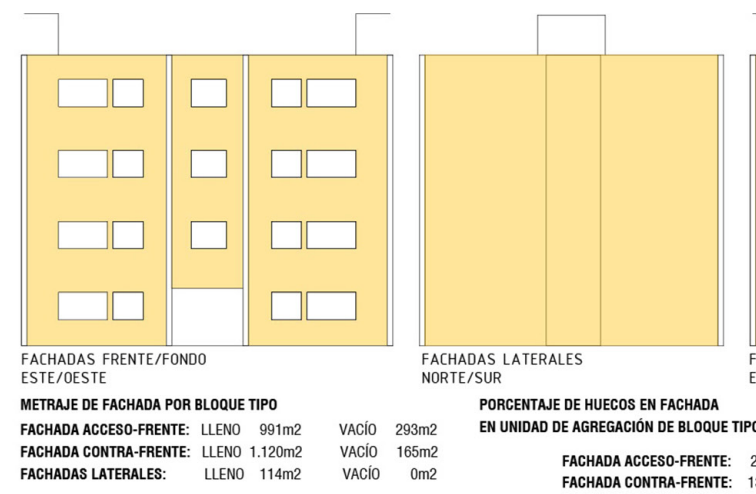
FACHADAS
NORTE/SUR

PORGENTAJE DE HUECOS EN FACHADA

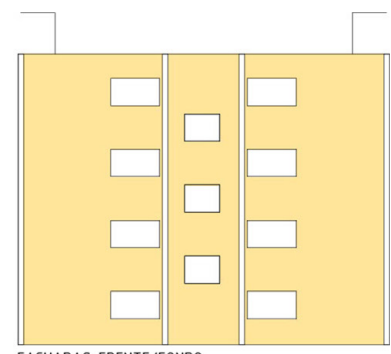
FACHADAS FRENTE/FONDO
ESTE/OESTE EN UNIDAD DE AGREGACIÓN DE BLOQUE TIPO FACHADA ACCESO-FRENTE: $23 \%$ FACHADA CONTRA-FRENTE: $13 \%$
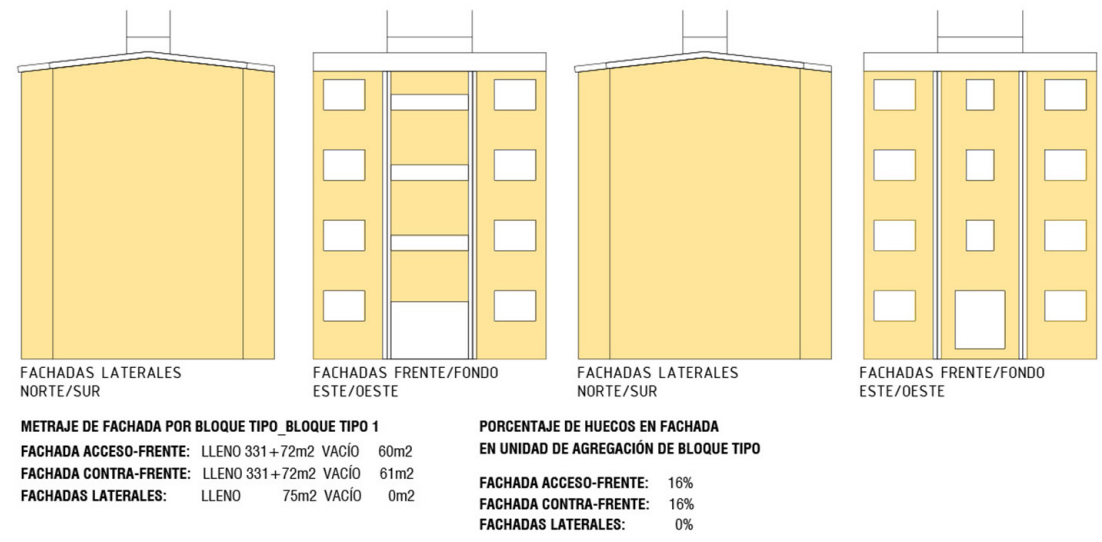
piso los que conforman un recinto espacial tridimensional próximo a una calle interna o al perímetro del conjunto (Figuras 6 y 7). La quinta fachada, la cubierta, es un territorio no explorado en estos conjuntos, siendo techos con una leve pendiente en dos aguas, de hormigón armado, con buenas vistas y con capacidad de soporte para ser horizontalizada, pavimentada o recibir una construcción liviana, con un área en todos los CHs de $40000 \mathrm{~m}^{2}$ de suelo aéreo.
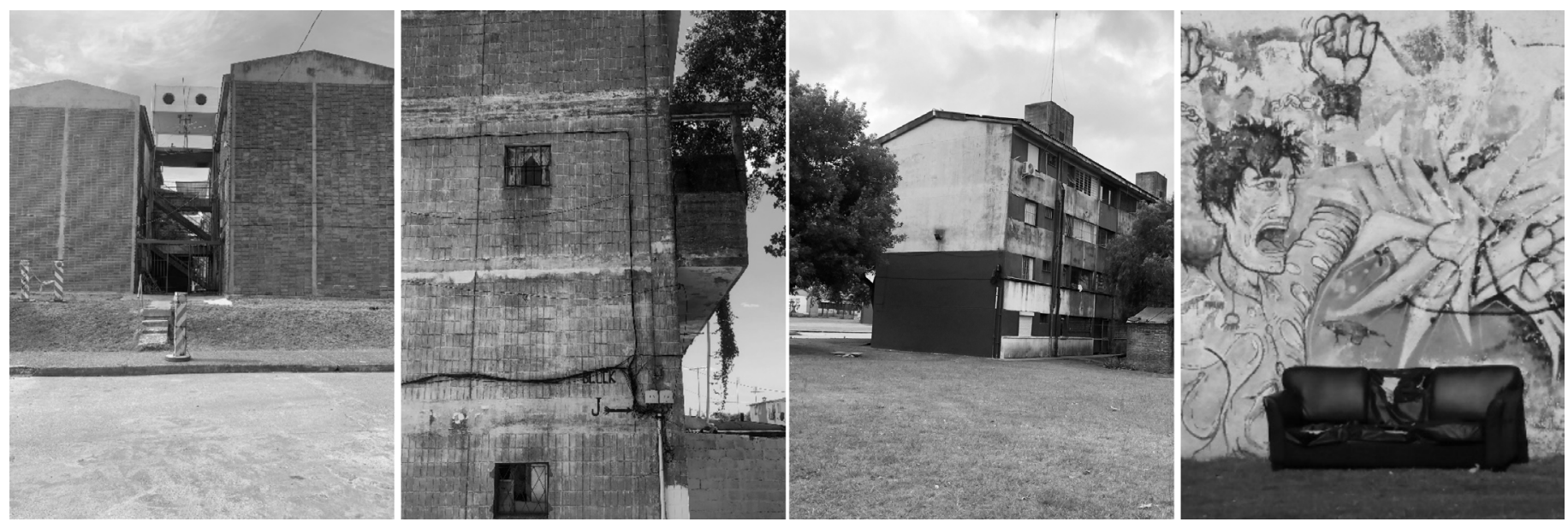

Activaciones. Ocupar las fachadas no habitadas.

Estas fachadas se presentan como oportunidades para transformar y rehabitar los conjuntos habitaciones.

La intervención en los testeros permite modificar las unidades de los extremos de los bloques y agregar programas colectivos en el espacio testero-piso.

La intervención en la cubierta permite ganar un territorio arriba del todo como espacio transitable para crear programas al aire libre (huerta, solárium, espacio parrillero, espacios para actividades de distintas franjas etarias, espacio picnic, observatorio, etc.), apoyado con el agregado de un ascensor, mejorando la accesibilidad general.

\section{Escala L_Del espacio intermedio al espacio-piso}

Lo colectivo dentro del conjunto es fundamental para la creación de comunidad e identidad respecto al espacio habitado favoreciendo la participación, comunicación e interacción. Montaner y Muxí (2006) se refieren a la importancia de los espacios intermedios para fomentar los valores de sociabilidad, solidaridad y civismo entre la comunidad.

El espacio intermedio no existe en la tipología de los bloques de los conjuntos, siendo el corte interior-exterior abrupto. Algunos núcleos de escaleras y puentes de circulación que vinculan bloques y techan los accesos o las calles corredor de algunos conjuntos, son leídos como espacios intermedios (Figuras 8 y 9 ).
Figura 7: Testeros de los CHs. Fuente: Fotos G. Ré y F. Cabrera. 


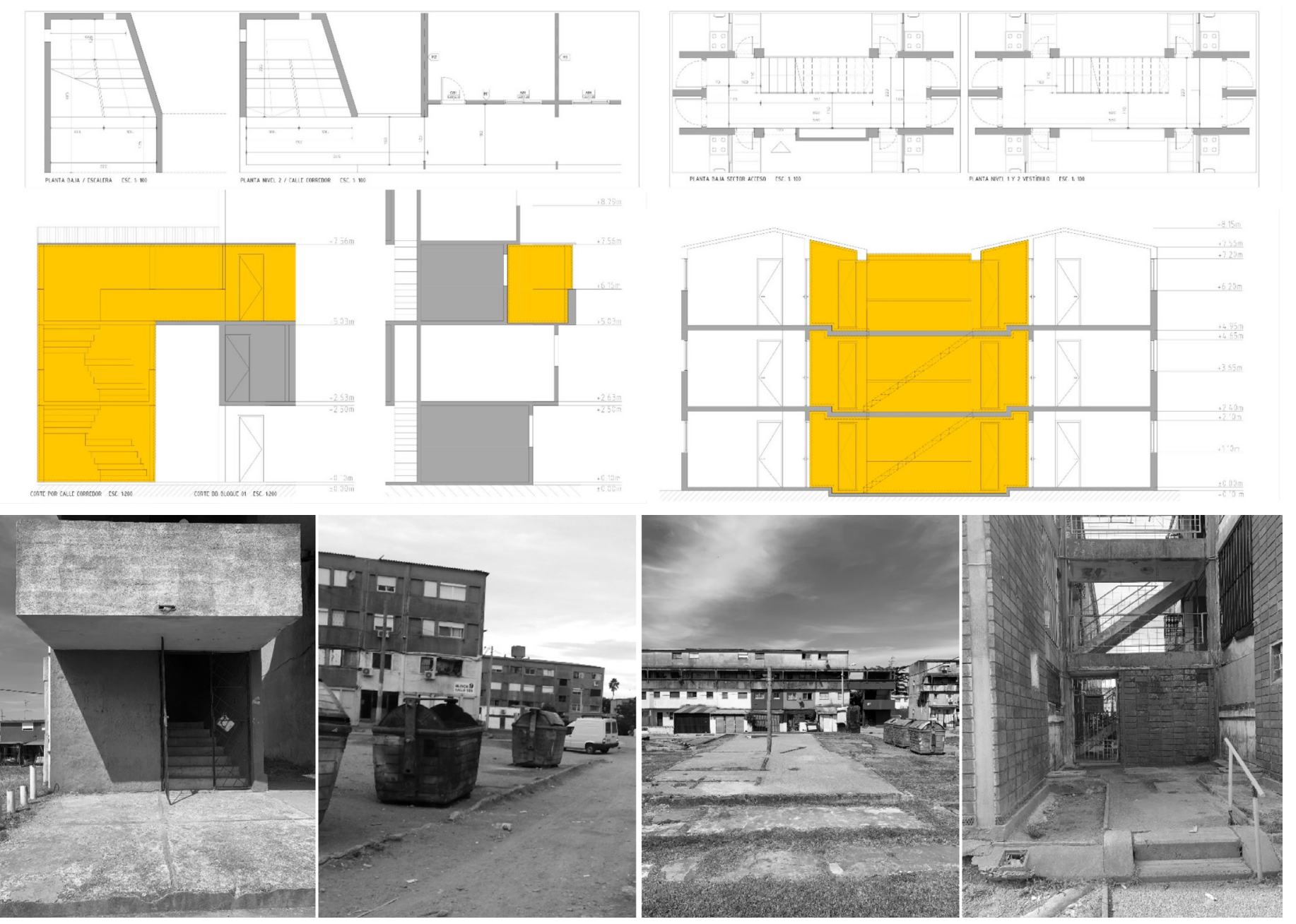

Figura 8 [arriba]: Circulaciones, MAM Tema: Interior, G, CH 26-38 y 83-8687. Elaboración propia.

Figura 9 [abajo]: "Espacios intermedios" en los CHs. Fotos G. Ré y F. Cabrera.
Activaciones. Folies

Como espacio intermedio de los conjuntos se propone la creación de puntos que operan como nodos de estar, los que llamaremos folies. Con esta expresión se nombran sectores dispersos de actividad, desde una pequeña superficie de suelo pavimentado a un espacio programático. El término traducido como rareza o peculiaridad es utilizado por Bernard Tschumi en el Parc de la Villette de París (1982-1998) donde las folies son interpretadas, no como locuras formales, sino como elementos referenciales de una grilla que estructura un complejo espacio urbano. Estos puntos diseminados por el conjunto se convierten en espacios capaces de inducir la interacción de los habitantes conformando una red de espacios intermediarios activos.

\section{Escala XL_Calles}

En los barrios donde se insertan estos conjuntos, periféricos en su mayoría, es casi inexistente la urbanidad. Los espacios abiertos y la calle de estos barrios se presentan como una infraestructura vacía de contenido y escala peatonal, el común denominador son los grandes predios. Mientras que el perímetro de una manzana convencional es del orden de 340 metros, el perímetro de las manzanas en que se insertan estos CHs puede llegar hasta 2 kilómetros. En la misma línea de razonamiento de las condiciones urbanas del entorno, interesa destacar los espacios como plazas, plazuelas, espacios libres y canteros centrales de avenidas, espacios abiertos potenciales si se integran a los circuitos urbanos peatonales (Figuras 10 y 11). 


\section{MANZANAS_ÁREA Y PERÍMETRO}
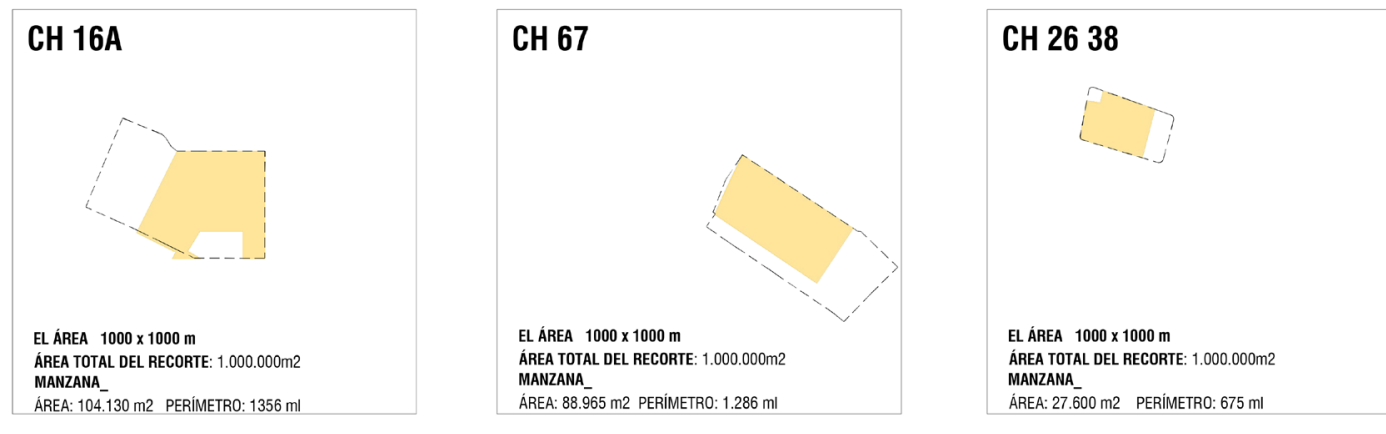

ESPACIOS PÚBLICOS EN EL ÁREA 1000x1000_ FUENTE WEB SIG MONTEVIDEO CH 16A

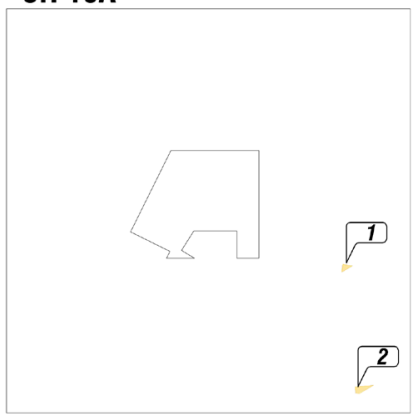

\section{CH 67 | 838687}

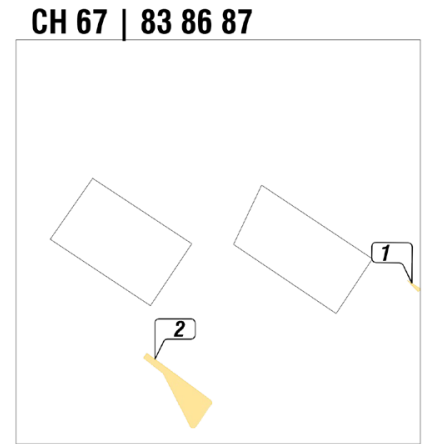

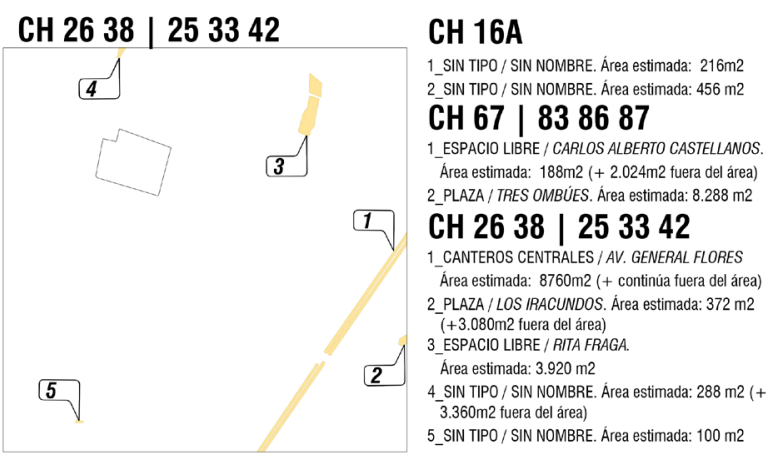
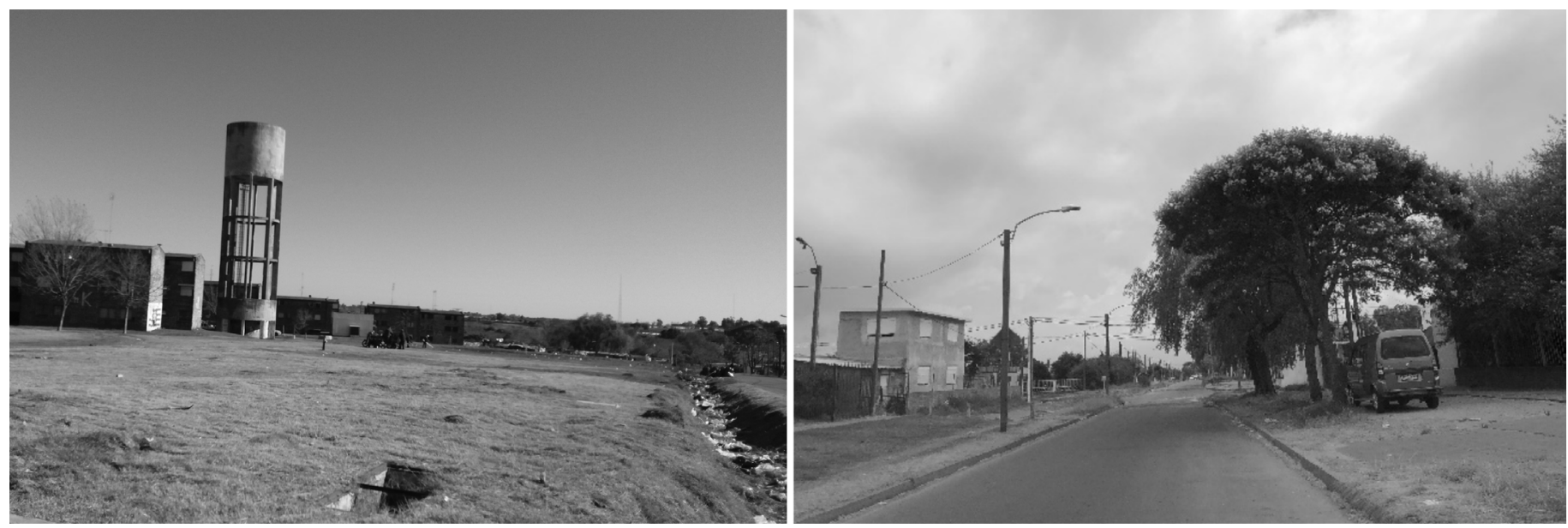

Activaciones. Ganar la calle

Ganar la calle (Borthagaray, 2010), urbanizar la calle de contacto del conjunto con la ciudad, dotarla de transitabilidad, escala y contenido, intervenir en los microespacios de proximidad del barrio siguiendo los principios del urbanismo táctico con proyectos colaborativos y de bajo costo, acciones que promuevan la formación de comunidad e identidad con el entorno habitado.
Figura 10 [arriba]: Manzanas del área, MAM, Eje: Exterior, XG. Elaboración propia.

Figura 11 [abajo]: Calles del entorno de los CHs. Fotos G. Ré y F. Cabrera.

\section{Imaginarios_ensayos proyectuales}

\section{Proyecto Escala XS + S_PLUG IN}

Curso: TFC, DEAPA. Propuesta CH+ ENZIMAS. 2017-2018

Autores: Guillermina Re, Camila Núñez

Escalas | Activaciones: XS_ Ventana / $S_{-}$Balcón / $M_{-}$Fachadas, Cubierta. 
ESCALA UNIDAD [...] se proponen en el exterior, [...] "extensiones" que suman un ambiente polifuncional a las unidades de vivienda [...] Extraído de la memoria del proyecto (Figura 12)

\section{LA ESTRUCTURA CONECTADA}

El edificio incorpora estrategias para optimizar el uso de la energía eléctrica (...) para el acondicionamiento térmico de las viviendas $y$ el calentamiento de agua de uso sanitario.

En cuanto al acondicionamiento térmico, se opta por sistemas pasivos, que reduzcan la necesidad de equipos de acondicionamiento mecánico. El agua de uso sanitario utiliza un sistema activo de energia renovable, que reduce el consumo eléctrico.

Las extensiones de la vivienda cuentan con un gran porcentaje de superficie vidriada en fachada. Esto maximiza la captación de la radiación solar (...) se utiliza el efecto invernadero como un sistema de calefacción pasivo (...)

Las unidades de dos y tres dormitorios son doblemente orientadas, por lo que la ventilación cruzada puede utilizarse para regular el aumento de temperatura.

Se modifican las condiciones de los muros de fachada de modo de aumentar la aislación térmica de las unidades. Algunos muros exteriores se convierten en interiores luego de agregarse las extensiones de vivienda. Aquellos que permanecen exteriores, incorporan paneles de fachada tipo VMZinc, que aumentan la aislación térmica de los aumentan la aislación térmica de los
mismos, a la vez que convierten la fachada en ventilada.

En aquellas fachadas vidriadas, se colocan paneles móviles que permiten regular la radiación solar directa sobre las mismas. (...)

Los colectores solares se instalan en la cubierta de los edificios, para pre-calentar el agua de uso sanitario. (...) Este sistema reduce el consumo eléctrico del edificio.

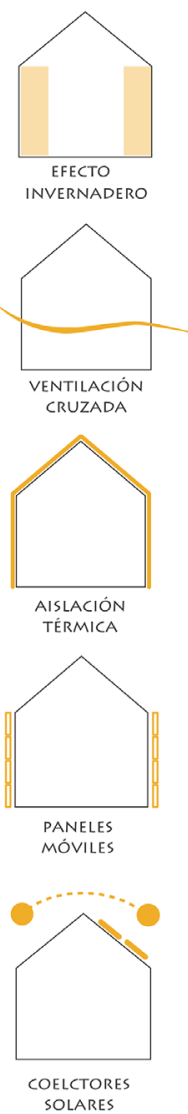

Figura 12: Plug in. Elaboración de los autores.
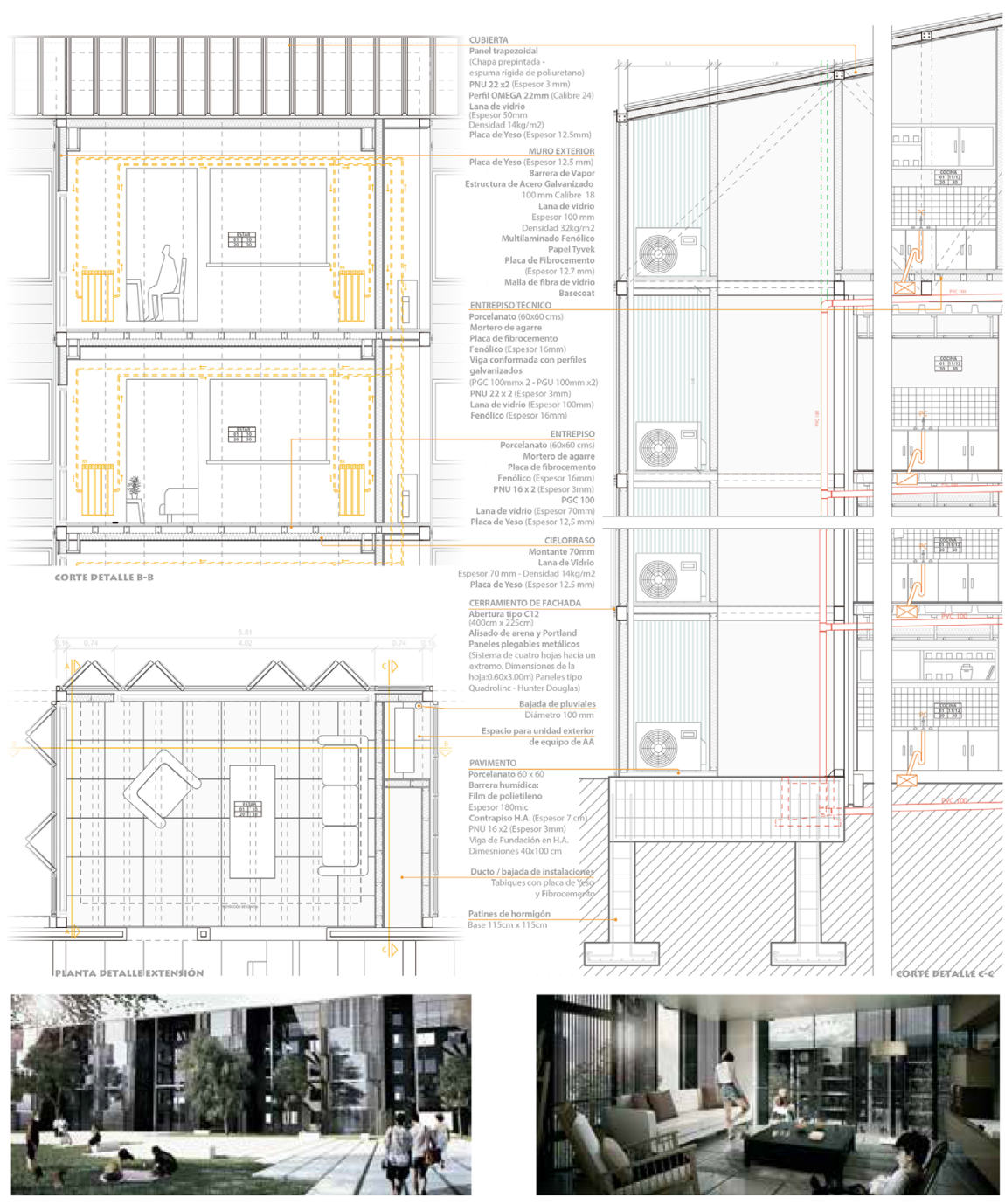

\section{Proyecto Escala $M_{-}$RE PARCELAR}

Curso: CH+. Maestría en Arquitectura. 2018

Autores: Arq. Natalie Cordero Arq. Natalia Fleitas Arq. Christian Flores

Escalas | Activaciones: $M_{-}$Testeros / $L_{-}$Pisos / XL_ Espacio intermedio-calle

Oportunidad. Cada testero da frente a un trapecio que se concibe como una nueva parcela, una nueva superficie de propiedad colectiva. ... Cada bloque se verá renovado mediante una complementación programática distintiva - ... El espesor es la herramienta conceptual (Cordero, Fleitas, Flores, 2018) (Figuras 13 y 14). 


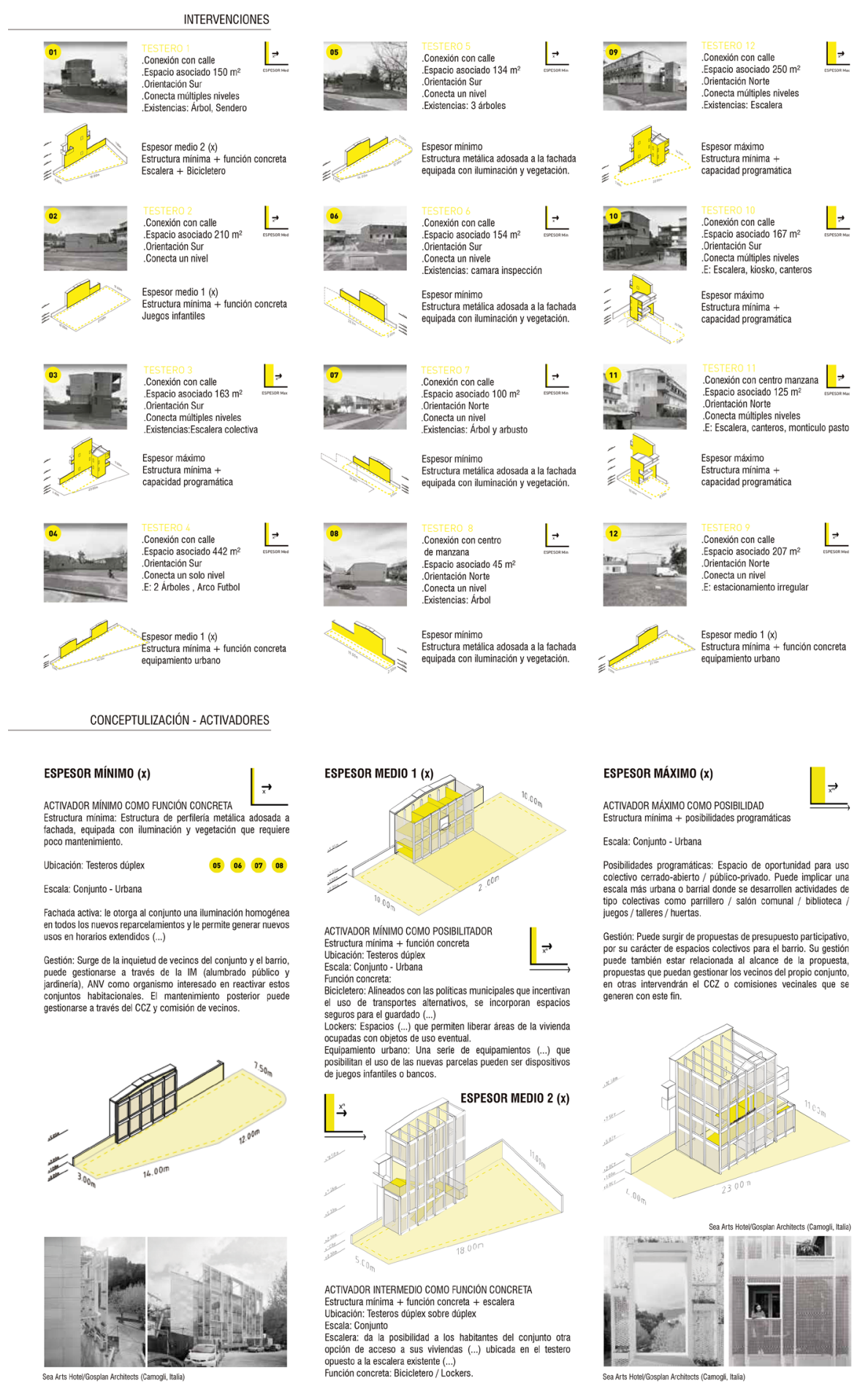

\section{Proyecto Escala L_ACUERDOS}

Curso: TIP 1. Programa I+P. 2017

Autores: Arq. Cotignola, Arq. Preziosi, Arq. Saettone, Arq. Trias, Arq. Ursic

Escalas | Activaciones: XS_Ventana / $S_{-}$Balcón / $M_{-}$Testeros, Fachadas, Cubierta / L_ Intermedios

El valor de lo colectivo.

... Una ocasión de reflexionar sobre la vecindad implicada, haciendo énfasis en la afirmación de las relaciones entre las personas, y su convivencia... (Cotignola, Preziosi, Saettone, Trias, Ursic, 2017, p. 5) (Figuras 15 y 16). 


$\begin{array}{lllllll}\text { C } & \text { U } & \text { E } & \mathrm{R} & \mathrm{D} & \mathbf{O} & \mathrm{S}\end{array}$

Los "acuerdos" como mecanismo generador de nuevos dominios; una propuesta conciliadora, que se define en micro acciones de consenso.

Apoyar la acción en la capacidad de organización latente en el sitio, invitando a los habitantes a la construcción de múltiples acuerdos capaces de generar infinitas configuraciones del espacio colectivo.

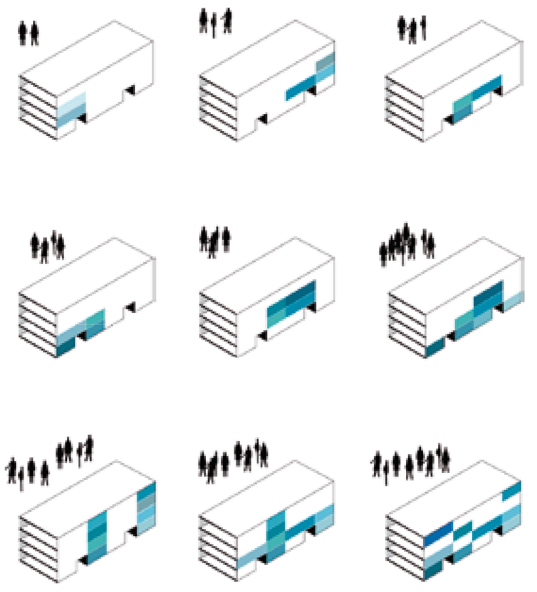

Promover asociaciones que definan nuevos entornos de domesticidad; diversos, flexibles, temporales o permanentes, basados en sistemas de comportamiento abiertos, emergentes, imprevisibles y sobre todo autorregulables.

Se trabaja sobre una mirada interescalar, invirtiendo la lógica habitual de generación del proyecto urbano; un recorrido desde la micro intervención hacia la definición de ciudad, confiando en la capacidad de lo edilicio para operar en la esfera de lo urbano.

\section{$\begin{array}{llllllll}\text { D } & \text { O } & \text { M } & \text { I } & \text { N } & \text { I } & \text { O } & \text { S }\end{array}$}

Se plantea trabajar sobre la noción de "dominios" como ámbitos plausibles de ser apropiados.

Activar el vacío existente, buscando una asociación e intersección de dominios que redefina la dicotomía entre lo público y 10 privado, posibilitando múltiples situaciones intermedias capaces de involucrar nuevos actores, hoy ausentes en la escena colectiva.

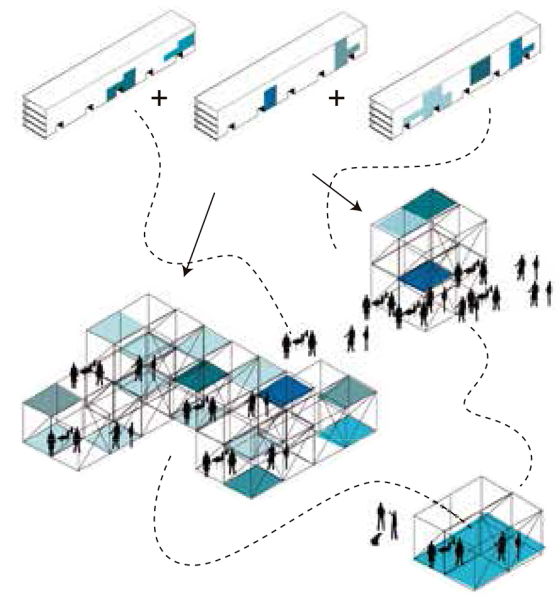

Alterar los bordes, generando nuevos dominios diversos en tipo y dimensión.

Sitios de encuentro, permanentes o temporales, a veces imprevistos, que posibiliten la apropiación y promuevan nuevos ámbitos de socialización, de otra convivencia.

Se trata de inventar miradas, desafiar los límites establecidos explorando caminos que logren descubrir nuevas relaciones y nuevos significados de lo existente. $\begin{array}{llllllll}\text { S } & \mathbf{O} & \mathrm{P} & \mathbf{O} & \mathrm{R} & \mathrm{T} & \mathrm{E} & \mathrm{S}\end{array}$

El soporte como medio, como instrumento arquitectónico que viabiliza y define espacios que tendrán diferentes manifestaciones en función del alcance, la escala, y el contexto, en el cual operen.

Intervenciones de baja energía que habiliten nuevos territorios sin generar grandes cambios en las estructuras existentes.

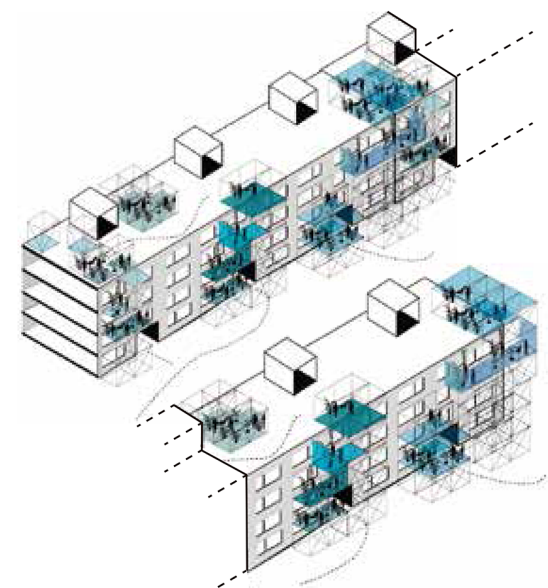

Proponer soportes como un sistema abierto capaz de trabajar sobre lo existente, una suerte de puzzle de fragmentos, que pueda desarrollarse de forma natural atendiendo a los posibles acuerdos que se establezcan.

Estos acuerdos se definen a partir de las distintas Unidades de gestión que los promuevan, de los Usos que estos habiliten, de los Sitios que colonicen, y de los Dominios sobre los que operen.

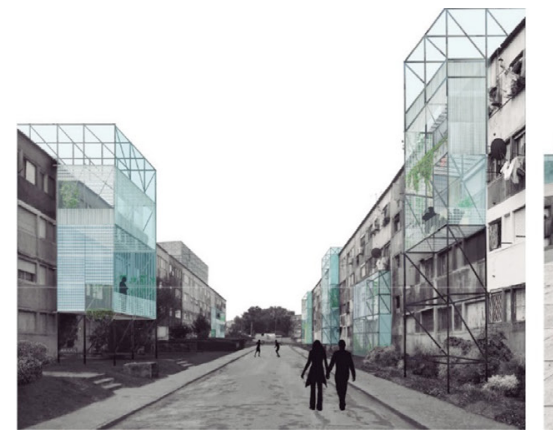

Figura 15 [arriba]: Acuerdos, esquemas conceptuales. Elaboración de los autores.

Figura 16 [abajo]: Acuerdos, espacios intermedios. Elaboración de los autores.

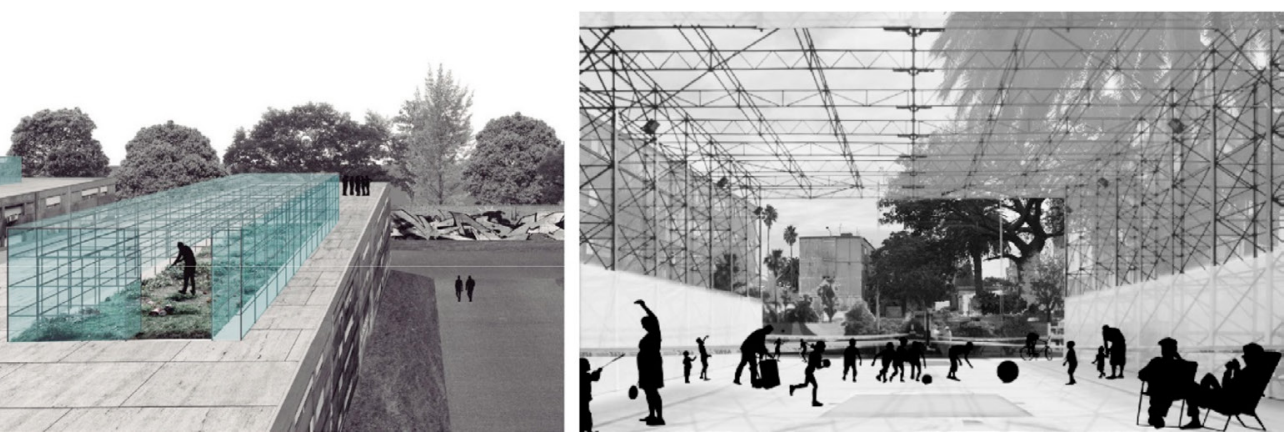

Curso: TIP 1. Programa I+P. 2017

Autores: Arq. L. Acosta, Arq. A. Arbelo, Arq. L. Ardanche, Arq. F. Bergamino, Arq. A. Varela, Arq. J. Viñar.

Escalas | Activaciones: $L_{-}$Intermedios / XL_Calles, Micro espacios públicos

... Resonancia. En el proceso, el grado de interacción de cada acontecimiento depende, de su mayor o menor eficacia para "resonar" en el sistema, y al mismo tiempo para transferirlos dotándolos de nuevas energías y por lo tanto de nuevos movimientos impulsores (Acosta, Arbelo, Ardanche, Bergamino, Varela, Viñar, 2017, p. 9) (Figuras 17 y 18). 


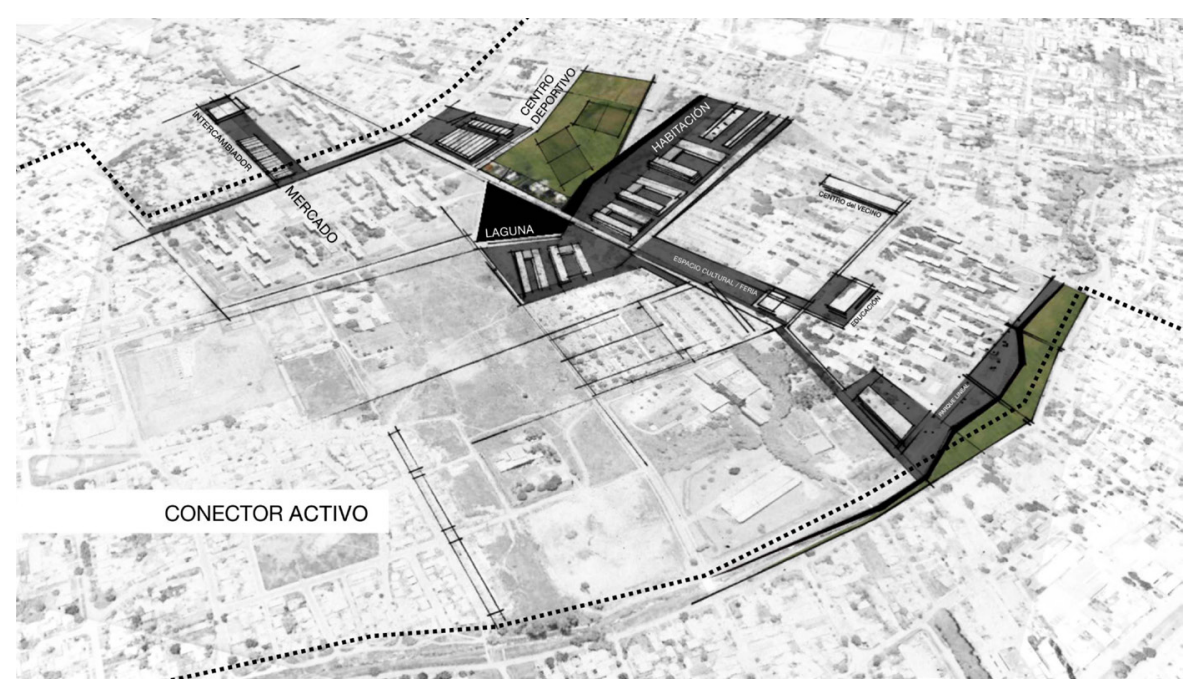

Figura 17 [izquierda]: Conector Activo, espacios de oportunidad. Elaboración de los autores.

Figura 18 [abajo]: Conector Activo, intervenciones en vacíos y programas existentes. Elaboración de los autores.
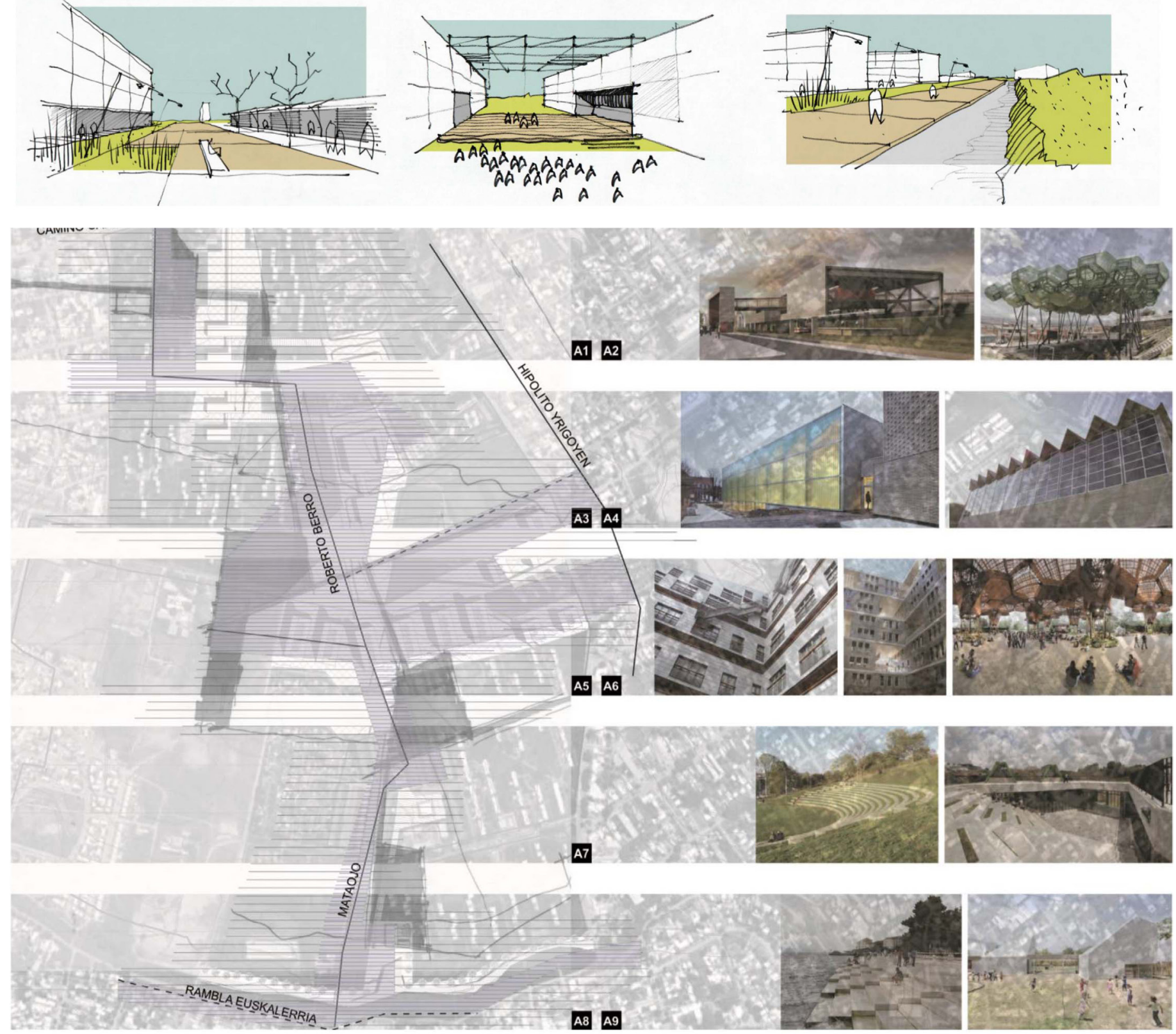


\section{Referencias bibliográficas}

Borrego, Ignacio (2006). Editorial: Arquitectura enzimática. En Arquitectos, 179, Revista del CSCAE, Madrid.

Borthagaray, Andrés (2010). ¡Ganar la calle! Compartir sin dividir. Buenos Aires: Infinito.

Lacaton, Anne, Druot, Frederic y Vassal, Jean-Philippe (2007). Plus, La Vivienda Colectiva. Territorio De Excepción. España: Editorial GG.

López Medina, José María (2012) El diseño participativo en programas de rehabilitación de vivienda (Tesis doctoral). ETSA- Universidad de Sevilla, España.

Montaner, Josep María y Muxí, Zaida. (2006). Habitar el presente. Vivienda en España: Sociedad, Ciudad, Tecnología y Recursos. Madrid: Ministerio de Vivienda.

Monteys, Xavier, Mària, Magda, Fuertes, Pere, Puigjaner, Anna, Sauquet, Roger, Marcos, Carles... y Linares, Oscar y colaboradores Grupo de investigación HABITAR (2010). Rehabitar. Barcelona: Departamento de Proyectos Arquitectónicos-UPC.

Nahoum, Benjamín (2008). De la autoconstrucción individual a las cooperativas pioneras. En Nahoum,
Benjamin (Ed.), Una historia con quince mil protagonistas. Las cooperativas de vivienda por ayuda mutua uruguayas (pp. 24-31). Montevideo: Intendencia Municipal de Montevideo; Junta de Andalucía; Agencia Española de Cooperación.

Pelli, Víctor Saúl (2010). La gestión de la producción social del hábitat. Hábitat y Sociedad, 1, 39-54. Recuperado el 4 de diciembre de 2020 de: https:/ / dialnet.unirioja.es/servlet/ articulo? codigo=3928730.

Ruiz Cabrero, Gabriel, investigador principal del grupo NuTAC, Escuela Politécnica de Madrid (2009). $I+D+S$ : Futuros de la vivienda social en 7 ciudades. Recuperado el 15 de agosto de 2017 de: https:/ / apps.fomento.gob.es/CVP/handlers/pdfhandler. ashx?idpub=BAW004.

Vigliecca, Héctor (2012). O terceiro territorio, en V.AA., Monolito \#7. Habitacão social em Sao Paulo (pp. 92-99). San Pablo: Monolito.

Cabrera Recoba, Andrés (2021). Aportes para el reproyecto de conjuntos habitacionales vulnerables. Micro acciones que promueven la exterioridad. Hábitat y Sociedad, 14, 339-352.

<https://doi.org/10.12795/HabitatySociedad.2021.i14.018> 